\title{
The Effect of Re-engineering of Administrative Processes in Achieving the Competitive Advantage of Sustainable in Five-Star Hotels in Jordan - Field Study
}

\author{
Prof. Suleiman Mustafa EL-Dalahmeh \\ Faculty of Economics and Admirative sciences \\ Accounting Department Jerash University \\ E-mail: Dr.el-dalahmeh97@live.com
}

Received: Jan. 9, 2019 Accepted: March 26, $2019 \quad$ Published: June 1, 2019

doi:10.5296/ajfa.v11i1.14353 URL: https://doi.org/10.5296/ajfa.v11i1.14353

\begin{abstract}
The main aim of the research was to identify the effect of Re-engineering of Administration Processes in Achieving the competitive Advantage of Sustainable in Five Star Hotels in Jordan. To achieve the objective of this study, a questionnaire distributed on 120 persons in Five Star Hotels in Jordan. 90 returned with a rate of $75 \%$. The results of the study showed that there is a significant statistical effect at the level of significance of $\alpha \leq 0.05$ for the re - engineering of administrative processes in achieving sustainable competitive advantage in five - star hotels in Jordan in the following dimensions:
\end{abstract}

- *Leadership * - Ability to analyze * - Advanced design * - Organizational communication * - Continuous improvement

Strategic Planning. The total score of the mean of the study instrument was 4.43 and with a standard deviation of 0.35 and $88.6 \%$ at a very high degree.

The results of the statistical analysis revealed the realization of the sample of the study in the investigated hotels, the extent of the effect of re-engineering the administrative processes in all its dimensions in achieving the competitive advantage.

Based on the results of hypotheses tested, the six null hypotheses of the study were rejected. In the light of the findings, the researcher recommended that:

1- The need to convince the management of hotels and hotel staff the importance of the application of re-engineering of administrative processes to achieve competitive advantage sustainable 


\section{Macrothink}

Asian Journal of Finance \& Accounting ISSN 1946-052X 2019, Vol. 11, No. 1

2- Utilizing the potential of graduates of new universities from the faculties of economics, administrative sciences and information technology.

Keywords: Re-engineering, administration processes, Five Stars Hotels, Competitive advantage of Sustainable. 


\section{Macrothink}

\section{Introduction}

The re-engineering of administrative processes is one of the important administrative directions that lead to the process of change in economic establishments so that the establishment starts work again to reduce the cost of the service or product without affecting the quality. The business environment is currently facing a competitive situation, with the openness of the world, the strength of competition, the opening of markets and the technological development that have led economic organization to keep pace with these changes in order to maintain their continuity.

This study came here to examine the impact of re-engineering of administrative processes in achieving of sustainable competitive advantage in five-star hotels in the Jordan. Hotel services are based on many factors and components to produce the tourist able product (accommodation and food) and use many of workers. Therefore, hotel services are complex and go through many stages.

\section{The problem of the study}

The problem of the study represented in:

The effect of re-engineering of administrative processes in achieving the competitive advantage of sustainability in five-star hotels in Jordan?

In the light of this problem, a series of sub-questions arise as follows:

1- Is there an effect of leadership in achieving the competitive advantage of sustainable in fivestar hotels in Jordan?

2- Is there an effect of the ability to analyze on achieving the competitive advantage of sustainable in five-star hotels in Jordan?

3- Is there an effect of redesign in achieving the competitive advantage of sustainable in fivestar hotels in Jordan?

4- Is there an effect of organizational communication in achieving the competitive advantage of sustainable in five-star hotels in Jordan?

5- Is there an effect of continuous improvement in achieving the competitive advantage of sustainable in five-star hotels in Jordan?

6- Is there an effect of strategic planning impact in achieving competitive advantage of sustainable in five-star hotels in Jordan?

\section{Objectives of The Study}

The main objective of the study is:

1. To know the impact of re-engineering of administrative processes on achieving sustainable competitive advantage in five star hotels in Jordan. 
The importance of the study: This study derives its importance from its focus on the importance of the components that constitute the competitive advantage of the Jordanian national economy and its representation in human capital.

\section{Hypotheses of the study}

HO1: There is no statistically significant effect at level $\alpha \leq 0.05$ for re-engineering of administrative processes in achieving competitive advantage sustainable in five-star hotels in Jordan

The following hypotheses are derived from the main hypothesis: -

HO1.1: There is no statistically significant at level $\alpha \leq 0.05$ for leadership in achieving competitive advantage sustainable in five-star hotels in Jordan

HO1.2: There is no statistically significant effect at level $\alpha \leq 0.05$ for the ability to analyze in achieving competitive advantage sustainable in five-star hotels in Jordan

HO1.3: There is no statistically significant effect at level $\alpha \leq 0.05$ for redesign in achieving competitive advantage sustainable in five-star hotels in Jordan

HO1.4: 9There is no statistically significant effect at level $\alpha \leq 0.05$ for organizational communication in achieving competitive advantage sustainable in five-star hotels in Jordan

HO1.5: There is no statistically significant effect at level $\alpha \leq 0.05$ for continuous improvement in achieving competitive advantage sustainable in five-star hotels in Jordan

HO1.6: There is no statistically significant effect at level $\alpha \leq 0.05$ for strategic planning in achieving competitive advantage sustainable in five-star hotels in Jordan

\section{Determinants of study}

1 -The scarcity of the Arabic and English studies in the subject of the study.

2 - weak cooperation of some hotels management with the researcher in conducting personal interviews with employees.

\section{Limitations of the study}

The study was limited to five-star hotels located in the Jordanian capital (Amman).

6.1 Reengineering of administrative processes in achieving sustainable of competitive advantage

The concepts presented by the researchers on the re-engineering of administrative processes have been varied due to the continuous and rapid modernization processes faced by business organizations throughout the world. Accordingly, the reengineering of administrative processes can be considered as an integrated concept consisting of the following conventional concepts:

1- Re (RE) a prefix means a new (Baalbaki,2012) 
2- Engineering. Means a set of methods and mechanisms for the application of mathematical and scientific rules to achieve practical results such as design, construction, efficiency and this will lead to re-engineering (Hasan,1997).

3- Administrative process. These are activities and functions such as operations, human resources, finance, administrative activity for senior management, research and development, public relations (Shamma, 2001).

Hammer \& Champy, (1993) view of process engineering is fundamentally rethinking, and radical redesign of key processes organized to achieve tremendous improvement results in modern gauges (service, quality, cost, and speed of performance). Process reengineering is defined as the overall transformation of work, restricted to all business processes, techniques, management systems, organizational structure and organizational values, with a view to achieving leapfrogging in the quality of performance of all businesses in the organization (Jalalie et al 2013)

\subsection{Motives of process reengineering:}

There are many motives from which the organizations start to re-establish operations (Yassin 2016)

1-Customers: Focusing on customers by identifying their needs, fulfilling their desires and designing work according to what suits him.

2- Change: A rule that should be adopted by all organizations aiming at reengineering their operations because they adopt change as a key input to develop the capabilities of enterprises

3- Competition: This is to change the method and tools of work and results by enabling employees to carry out their tasks.

\subsection{Objectives of process reengineering:}

The goals of process reengineering are summarized as follows (Ziglaris, 2000)

1. Customer focus, 2. Speed of implementation, 3. Process compilation, 4. Flexibility

5. Quality, 6. Innovation, 7. Product improvement (increase efficiency and effectiveness)

\subsection{The Importance of The Re-engineering of Administrative Processes:}

(Roberts 1994) The re-engineering of administrative processes derives its importance from the rapid change in the methods and mechanisms required by enterprises as a result of the engineering process engineering tool, the huge technological developments and the intense global competition. Therefore, the enterprises need administrative processes capable of dealing with changes Which will result in improvements in service and productivity, resulting in improved output quality to meet the needs and needs of customers (Roberts 1994). The importance of re-engineering management processes is thus efficient and effective the importance of process reengineering lies in the method of rapid and substantial improvement in performance. The improvement includes reducing the stages, stopping and cost of operations. 
Increasing their return as well as setting acceptable competitive prices (Hammer \& champy 1993)

1- A method of rapid and substantial improvement in the performance aspects. The improvement includes saving the stages, stopping and cost of operations and increasing their return or added value in addition to setting competitive prices (Al-Refai,2006).

2- Tool to deal with three types of organizations.

\subsection{Benefits of Re-engineering Processes:}

There are several important trends that are taking place in today's business environment and are related to the re-engineering process.

1- The re-engineering of administrative processes is the first starting point and is taken into account by the Executive Director to maximize the benefit to the Organization

2- Competition and the ability to make a profit

3- Working through the functional departments, including markets and customers on the other hand through

\subsection{Factors for Successful Administrative Processes Re-engineering}

According to (Lampathaki F.et al 2013):

1- Leadership, 2-Ability to analyze, 3- Redesign, 4- Organizational communication

5- Continuous improvement, 6- Strategic planning.

\subsection{Obstacles to The Application of Re-engineering of Administrative Processes:}

Venaik (2015) listed a set of obstacles to the application of re-engineering administrative processes are: Problems related to communication and lack of supported communication systems neglecting organizational culture of the organization resulting in organizational resistance of workers Problems related to not adopting a -culture of change or management Poor training and education systems Lack understanding of the management of the Organization of the concept of re-engineering operations and commitment Economy to the financial, material and human resources required for implementation.

\subsection{Sustainable Competitive Advantage}

Many researchers have presented diverse definitions of sustainable competitive advantage according to their views. (Harvey 1981) recognized the competitive advantage as a source that enhances the organization's position in the market by making profits by distinguishing it from its rivals in the areas of cost and excellence (Dickson 1992) As the new features obtained by the business organization, making it in a position of continuous progress in the relations with its competitors. He pointed out (Daft 2010) that the ability of the organization to increase its market share by keeping the low cost compared to competitors and the researcher believes that the competitive advantage is sustainable ability of the enterprise Excellence and uniqueness from other facilities by tapping the optimum internal capabilities and investment opportunities 
and transform the challenges and threats from the external environment into opportunities in order to provide products and high quality services to current and prospective customers.

\subsection{The Importance of Sustainable Competitive Advantage}

The competitive advantage is a positive indicator of the company's tendency to occupy a strong position in the market by acquiring a greater market share of competitors and increasing sales and profits (Qaryuti 2014). The importance of competitive advantage in (Evan,1993)

1-provide important support contributes to the success of business.

2- characterized by permanence and difficulty to imitate competitors

3-Provide orientation and motivation for the whole enterprise.

4-Provide a basis for future improvements.

5- Determined depending on the needs and desires of customers.

6- Availability of harmony between FAO and opportunities in the environment.

\subsection{Dimensions of Sustainable Competitive Advantage:}

In order to achieve the research objectives, the researcher will adopt the basic dimensions of the competitive advantage of sustainable:

Creative culture: works to provide an encouraging work environment and help creativity

Information technology: Information technology consists of two physical and mental components: computer equipment, automatic control and communication, while the mental side represents software, artificial intelligence, and software engineering.

Core competencies: the organizational skills and knowledge without which the organization does not exist that make the organization work better than any other organization and thus make it unique (Ajaj, Shibli, 2015)

Quality of service: Quality is one of the best standards and the most important to judge organizations in general and service organizations in particular

5Loyalty: organizational loyalty is an asset of the organization and its preservation is key to success in the organization (Assaf,2015).

\section{Methodology of The Study}

In order to achieve the objectives of the study, the researcher relied on the analytical descriptive approach for achieving data and information about the opinions and attitudes of the people whether it is written survey (questionnaire) or orally, and it is suitable for the purposes of the study which seeks to know the effect of independent variables on the dependent variable 
population of study

The study community consists of all directors, assistant managers and heads of financial and administrative departments in the five-star hotels in Jordan of the total 14. (hotels in Amman, 2017).

\subsection{Sample of The Study}

The questionnaire was distributed to a simple random sample consistent of (120) managers, assistant managers and heads of financial and administrative departments in the five-star hotels in Jordan, because their experience and knowledge of re-engineering processes, The number of questionnaires retrieved and valid for the statistical analysis was 90 (75\%) of the number of questionnaires distributed Statistically acceptable ratio

\subsection{Tests and Analysis of Results}

First, the stability of the study: To ascertain the stability of the study instrument, the stability coefficient was extracted in the Cronbach Alpha method and the total stability of the field of study was (0.78) which is excellent in this type of studies

Second, the study tool was authenticated: 1 . The apparent honesty of the study tool: In order to verify the validity of the study tool, the researcher presented it to 6 arbitrators from the faculty members of the accounting departments in the Jordanian universities, and after their opinion and observations, the paragraphs of the questionnaire were amended.

2. Exploratory constructional honesty of the instrument of measurement: The researcher will use exploratory analysis to test the independent variable scale (re-engineering of administrative processes) and measure the dependent variable to determine the dimensions covered by the scale and to identify the paragraphs that do not correlate with the scale structure and which should be excluded from the scale

A) The scale of the re-engineering of the administrative processes: To verify the adequacy of the sample and the existence of correlation between variables, the Kaiser-Meyer-Olkin Measure was used. The statistical value of this scale ranges between $0-1$ and the value of (1) The correlation model is reliable, and the global analysis will be more credible. As shown in Table 1, the Bartlett test indicates that there is a moral 
Table 1. KMO and Bartlett testing for reengineering of administrative processes

\begin{tabular}{|c|c|}
\hline Kaiser - Meyer- Olkin Measure & 0.725 \\
\hline \multicolumn{2}{|l|}{ Bartlett's Test of Sphericity } \\
\hline Approx. Chi-Square & 366.526 \\
\hline Df & 13 \\
\hline Sig & 0.000 \\
\hline
\end{tabular}

The results show that the value of KMO is 0.725 , which is greater than 0.05 , which is a large value. The results of Bartlett's test (366.526) are significant and based on these results, the correlation matrix is not a single matrix. Between vertebrae which are significant

B - the measure of competitive advantage: In the same way has been tested this measure, which includes 5 dimensions, namely, creative culture, information technology, material impotence, quality, loyalty, the researcher will use exploratory analysis as shown in Table 2

Table 2. KMO and Bartlett testing for reengineering of administrative processes

\begin{tabular}{|l|l|}
\hline Kaiser - Meyer- Olkin Measure & 0.840 \\
\hline Bartlett's Test of Sphericity & \\
\hline Approx. Chi-Square & 255.60 \\
\hline Df & 8 \\
\hline Sig & \\
\hline
\end{tabular}

Table 2 shows that the KMO (0.840) is larger than 0.05 and is significant for correlation between variables. The Bartlett's score of 255.60 indicates a significant correlation between the two paragraphs.

Statistical methods used: To analyze the study data, the researcher used the Statistical Package for Social Studies (SPSSS) using the following descriptive and analytical treatments:

The arithmetical averages, standard deviations and percentages to find the stability coefficient of the study tool used the researcher Kronbach Alpha Test the linear correlation problem Use the Kaiser-Meyer-Olkin Measure and Bartlett's Test of Sphericity 


\subsection{Testing hypotheses}

The main hypothesis: HO1: There is no statistically significant significance at $\alpha \leq 0.05$ for reengineering processes in achieving sustainable competitive advantage in five-star hotels in Jordan.

Using the linear logarithmic model and for the purpose of achieving this can be addressed as follows:

HO1.1 There is no statistically significant effect at the significance level of $\alpha \leq 0.05$ for leadership in achieving sustainable competitive advantage in five star hotels in Jordan

Table 3. The results of the regression analysis of the impact of leadership in achieving sustainable competitive advantage

\begin{tabular}{|c|c|c|c|c|c|c|c|}
\hline $\begin{array}{l}\text { Hypothesis } \\
\text { Result }\end{array}$ & $\begin{array}{l}\text { Sign } \\
(0.05)\end{array}$ & $\mathbf{F}$ & $\mathbf{R}^{2}$ & $\begin{array}{l}\beta \\
\text { Beta }\end{array}$ & $\begin{array}{l}\alpha \\
\text { Alpha }\end{array}$ & Dependent variable & $\begin{array}{l}\text { Independent } \\
\text { Variable }\end{array}$ \\
\hline Rejected & & 17.52 & $\% 18$ & 0.506 & 2.43 & $\begin{array}{l}\text { Sustainable of } \\
\text { competitive advantage }\end{array}$ & Leadership \\
\hline
\end{tabular}

The value of the table $\mathrm{F}$ at a level of significance $(0.05)=3.00$

The data in Table 3 show that the value of Beta $=0.506$ indicates that the change in leadership leads to an increase in the achievement of sustainable competitive advantage and therefore rejects the null hypothesis HO1.1 and accepts the alternative hypothesis which states "there is a statistically significant effect at the $\alpha \leq 0.05$ level To lead the sustainable competitive advantage of five-star hotels in Jordan" .

HO1.2: There is no statistically significant effect at significance level of $\alpha \leq 0.05$ for the ability to analyze in achieving sustainable competitive advantage in five-star hotels in Jordan

Table 4. The results of the regression analysis of the impact of the ability to analyze in achieving sustainable competitive advantage

\begin{tabular}{|l|l|l|l|l|l|l|l|}
\hline Hypothesis & Sign & $F$ & $R^{2}$ & $\beta$ & $\alpha$ & Dependent variable & Independent \\
Result & $(0.05)$ & & & Beta & Alpha & & Variable \\
\hline Rejected & & 24.22 & $\% 22$ & 0.523 & 1.696 & $\begin{array}{l}\text { Sustainable of } \\
\text { competitive advantage }\end{array}$ & Leadership \\
& & & & & & & \\
\hline
\end{tabular}

F value of the table at the level of significance $(0.05)$ and the degree of freedom $(80.1)=3.00$ 


\section{Macrothink

Table 4 shows that there is a significant effect on the ability to analyze in achieving sustainable competitive advantage. The calculated value of $\mathrm{f}(24.022)$ is greater than the tabular value at the level of significance 0.05 and below 80.1 degrees of freedom. R 2 interprets $22 \%$ The value of beta 0.523 indicates that the change in the ability to analyze by one unit leads to an increase in the achievement of sustainable competitive advantage by 0.523 and therefore reject the null hypothesis HO1.2 and accept the alternative hypothesis which states that "there is a statistically significant effect at the level of significance $\alpha \leq 0.05$ for the ability to analyze the probe Sustainable Competitive Advantage in Five Star Hotels in Jordan"

HO1.3: There is no statistically significant significance at $\alpha \leq 0.05$ for redesigning sustainable competitiveness in five-star hotels in Jordan

Table 5. The results of the regression analysis of the effect of redesign in achieving sustainable competitive advantage

\begin{tabular}{|l|l|l|l|l|l|l|l|}
\hline Hypothesis & Sign & F & $R^{2}$ & $\beta$ & $\alpha$ & Dependent variable & Independent \\
\hline Result & $(0.05)$ & & Beta & Alpha & & Variable \\
\hline & & 67.892 & $\% 45$ & 0.721 & 1.062 & $\begin{array}{l}\text { Sustainable of } \\
\text { competitive advantage }\end{array}$ & Leadership \\
\hline
\end{tabular}

F value of the table at the level of significance $(0.05)$ and the degree of freedom $(80.1)=3.00$

Table 5 shows that redesign has a significant effect on achieving sustainable competitive advantage. The calculated value of $\mathrm{F}$ is 67,892 , which is greater than the tabular value at the level of 1.80 and $\mathrm{R} 2$ interprets $45 \%$ of the contribution to achieve competitive advantage. The value of beta 0.721 refers to That the change in redesign results in an increase in the competitive advantage by 0.721 and therefore rejects the null hypothesis HO1.3 and accepts the alternative hypothesis that "there is a statistically significant effect at the $\alpha \leq 0.05$ level of redesign in achieving sustainable competitive advantage 5 Star hotels Jordan"

HO1.4: There is no statistically significant effect at significance level of $\alpha \leq 0.05$ for organizational communication in achieving sustainable competitive advantage in five star hotels in Jordan 
Table 6. The results of the regression analysis of the impact of organizational communication on achieving sustainable competitive advantage

\begin{tabular}{|c|c|c|c|c|c|c|c|}
\hline Hypothesis & Sign & $\mathbf{F}$ & $\mathbf{R}^{2}$ & $\boldsymbol{\beta}$ & $\boldsymbol{\alpha}$ & Dependent variable & Independent \\
\hline Result & $(0.05)$ & & & Beta & Alpha & & Variable \\
\hline Rejected & & 173.62 & $\% 68$ & 0.672 & 1.280 & $\begin{array}{l}\text { Sustainable of } \\
\text { competitive advantage }\end{array}$ & Leadership \\
\hline
\end{tabular}

F value of the table at the level of significance $(0.05)$ and the degree of freedom $(80.1)=3.00$

Table 6 shows that there is a significant effect of organizational communication on the achievement of sustainable competitive advantage. In addition, the value of calculated $\mathrm{F}$ is 173.62, which is greater than the significance level of 0.05 and the degree of freedom is 1.80 . The value of R2 explains $68 \%$ of the contribution to achieving competitive advantage A beta value of 0.672 indicates that the change in organizational communication by one unit leads to increased achievement of the competitive advantage of 0.672 and therefore rejects the null hypothesis $\mathrm{HO} 1.4$ and accepts the alternative hypothesis that "there is a statistically significant effect at the $\alpha \leq 0.05$ Achieving competitive advantage Sustainable in five-star hotels in Jordan HO1.5: There is no significant statistical effect at the level of significance of $\alpha \leq 0.05$ for continues improvement in sustainable competitive advantage in five star hotels in Jordan

Table 7. The results of the regression analysis of the impact of continuous improvement in achieving sustainable competitive advantage

\begin{tabular}{|c|c|c|c|c|c|c|c|}
\hline Hypothesis & Sign & $\mathbf{F}$ & $\mathbf{R}^{2}$ & $\boldsymbol{\beta}$ & $\boldsymbol{\alpha}$ & Dependent variable & Independent \\
\hline Result & $(0.05)$ & & & Beta & Alpha & & Variable \\
\hline Rejected & & 36.382 & $\% 43$ & 0.646 & 1.281 & $\begin{array}{l}\text { Sustainable of } \\
\text { competitive advantage }\end{array}$ & Leadership \\
\hline
\end{tabular}

F value of the table at the level of significance $(0.05)$ and the degree of freedom $(80.1)=3.00$

Table 7 shows that there is an impact of continuous improvement in the achievement of sustainable competitive advantage. The calculated value of $\mathrm{f}$ is 36.382 , which is greater than the tabular value at the level of significance 0.05 and below the freedom level of 1.80 and R2 explained $43 \%$ of the contribution to achieving the competitive advantage and the value of beta is 0.646 The result indicates that the change in continuous improvement by one unit increases the competitive advantage by 0.646 and rejects the null hypothesis HO1.5 and accepts the alternative hypothesis that "there is a statistically significant effect at the $\alpha \leq 0.05$ level for 
continuous improvement in feature achievement Sustainable competitiveness In Five Star hotels in Jordan"

Table 8. The results of the regression analysis of the impact of strategic planning on achieving sustainable competitive advantage

\begin{tabular}{|c|c|c|c|c|c|c|c|}
\hline Hypothesis & Sign & $\mathbf{F}$ & $\mathbf{R}^{2}$ & $\boldsymbol{\beta}$ & $\alpha$ & Dependent variable & Independent \\
\hline Result & $(0.05)$ & & & Beta & Alpha & & Variable \\
\hline Rejected & & 118.466 & $\% 60$ & 0.554 & 1.455 & $\begin{array}{l}\text { Sustainable of } \\
\text { competitive advantage }\end{array}$ & Leadership \\
\hline
\end{tabular}

F value of the table at the level of significance $(0.05)$ and the degree of freedom $(80.1)=3.00$

Table 8 shows that strategic planning has an impact on achieving competitive advantage. The calculated value of $\mathrm{F}$ is 118.466 , which is greater than the tabular value at the significance level 0.05 and R2 explains $60 \%$ of the amount of competitive contribution. The value of beta 0.554 indicates that the change in strategic planning by One unit leads to an increase in achieving the competitive advantage by 0.554 and rejects the null hypothesis HO1.6 and accepts the alternative hypothesis that "there is a significant statistical effect at the level of $\alpha \leq 0.05$ for strategic planning in achieving sustainable competitive advantage in five star hotels in Jordan

\section{Results and Recommendations}

\subsection{Results}

The results of the study showed that there is a significant statistical effect at the level of significance of $\alpha \leq 0.05$ for the re - engineering of administrative processes in achieving sustainable competitive advantage in five - star hotels in Jordan in the following dimensions:

- *Leadership * - Ability to analyze * - Advanced design * - Organizational communication * - Continuous improvement

Strategic Planning. The total score of the mean of the study instrument was 4.43 and with a standard deviation of 0.35 and $88.6 \%$ at a very high degree.

The results of the statistical analysis revealed the realization of the sample of the study in the investigated hotels, the extent of the effect of re-engineering the administrative processes in all its dimensions in achieving the competitive advantage.

There is harmony and consensus in the views and responses of the sample of the study to adopt the reengineering of administrative processes to achieve its goal and objectives with the highest degree of efficiency and effectiveness. 


\subsection{Recommendations}

1- The need to convince the management of hotels and hotel staff the importance of the application of re-engineering of administrative processes to achieve competitive advantage sustainable

2- Utilizing the potential of graduates of new universities from the faculties of economics, administrative sciences and information technology.

\section{References}

Assaf, Mahmoud Abdel Majeed. (2015). A proposed strategy for managing creativity as an entry point for achieving competitive advantage in the institutions of higher education and the Palestinian Ministry of Education

Baalbaki, Munir. (2012). The near axis Dictionary English Arabic, edition 25.

Daft, Richard. L. (2010). Organization theory and Design, $7^{\text {th }}$ ed, south. western collage publishing, USA.

Available: https://books.google.jo/books?id=CmFjF5tNmuEC\&dq=Organization+Theory+and+Design+ Richared $+2010 \& h \mathrm{~h}=$ ar\&sa $=\mathrm{X} \& \mathrm{ved}=0 \mathrm{ahUKEwj-}$ yJyk6JzhAhWJy6QKHdvCCUoQ6wEILDAA

Dick Son, peter R. (1992). Toward a General Theory of Competitive Rationality. Journal of Marketing, $\quad 56 \quad$ (January): $\quad$ New $\quad$ York $1992 . \quad$ Available: https://www.jstor.org/stable/1252133?seq=1\#page_scan_tab_contents

Hammer, Micheal, \& champy, James. (2001). Re-Engineering the corporation; A manifesto for business Revolution, Harper Collins Publisher Inc, Adobe A crobat E-book Reader Edition. Available: https://books.google.jo/books?id=mjvGTXgFl6cC\&printsec=frontcover\&dq=ReEngineering + the + corporation $+;+\mathrm{A}+$ manifesto + for + business + Revolution,++ Harper + Collins $\&$ $\mathrm{hl}=$ ar\&sa $=$ X\&ved=0ahUKEwj0g_fb6JzhAhXJ0aQKHZ1kBQMQ6AEIJzAA\#v=onepage\&q $=$ ReEngineering $\% 20$ the $\% 20$ corporation $\% 20 \% 3 \mathrm{~B} \% 20 \mathrm{~A} \% 20$ manifesto $\% 20$ for $\% 20$ business $\%$ 20Revolution $\% 20 \% 2 \mathrm{C} \% 20$ Harper $\% 20$ Collins\&f=false

Hasnsen, G.A. (1997). Automating Business process Re-Engineering, $2^{\text {th }}$ Ed, prentice - Hall. Jalali M. Maroofi.F. Navid, j., \& Mohammady R. (2013). Evaluation the Relationship between ICT - adoption and business process Re- engineering in Small and medium saized enterprises of Kerman shan province. International research journal of applied and basic Sciences, 4(3). Available: http://www.irjabs.com/files_site/paperlist/r_711_130328101558.pdf

Lampathaki F. Koussouris, S., \& psarras, J. (2013). BPK lifecycle, Decision support systems Labortary, National technical university of Athens

Mahmoud, Degla Mahdi. (2007). The Effect of Re-Engineering on Achieving Competitive Advantages. Technical Journal, 20(2). Helwan University Egypt. 
Porter, M., \& Kramer, M. (2006). Strategy and society: the link between competitive advantage and corporate social responsibility. Harvard business review. Available: https://www.sharedvalue.org/sites/default/files/resource-files/Strategy_and_Society.pdf

Qaryuti, Musa Qasim et al. (2014). The Role of Social Responsibility in Achieving Competitive Advantage Case Study in Zain Jordan Telecom journal of Administrative Sciences 41(1). University of Jordan. Available: https://journals.ju.edu.jo/DirasatAdm/article/view/5721

Raghvendra, M. (2013.) Competitive strategies for the 2st century: theory history and practice. Journal of the maritime foundation of India, 19(2).

Rifa'i, Mamdouh. (2006). Process Reengineering, i 1, Ain Shams for Printing and Publishing Cairo

Roperts, lon. (1994). Process Re-Engineering, the key to Achieving Break through Success. ASQ Quality press. Wisconsin. Available: https://asq.org/quality-press/displayitem?item $=\mathrm{E} 0830$

Shamma, Khalil. (2001). Principles of Management with a Focus on Business Management, Publishing House for Distribution and Printing - Amman

Venaik, A. (2015). Quality live risk level estimation of business process re-engineering efforts and effects with special reference to sector. Publication co., New York, USA

Yasin, Saad Ghaleb. (2016). Management Information Systems. Dar Al-Yazuri Publishing and Distribution Jordan

Zigiaris Sotiris. (2000). Business process Re-Engineering, A report Produced for the Ecfuded project. INNOREGIO project 